\title{
SFM India Oriented Guidelines for Ultrasound Establishments During the COVID 19 Pandemic
}

\author{
Ashok Khurana $^{1}$ - K. Aparna Sharma ${ }^{1} \cdot$ Sumitra Bachani $^{1} \cdot$ Gaurika Sahi $^{1}$. \\ Reema Kumar Bhatt ${ }^{1} \cdot$ Bimal Sahani $^{1} \cdot$ Mohit V. Shah ${ }^{1} \cdot$ Sunil Mehta $^{1}$. \\ Krishna Gopal $^{1}$ • T. L. N. Praveen ${ }^{1}$
}

Published online: 11 April 2020

(C) Society of Fetal Medicine 2020

\section{Background}

The International Society of Ultrasound in Obstetrics and Gynecology (ISUOG) has recently published guidance on the use of personal protective equipment (PPE) and other methods to reduce the hazard of SARS-CoV-2 infection for clinicians and sonographers undertaking ultrasound examinations $[1,2]$. The documents, however, clearly state that guidance in relation to PPE differs from country to country and region to region and that local guidance should be followed when this is available. This document attempts to fill that space in the context of heterogeneity and varied education level, economic status and cultural beliefs and practices in India.

As in the ISUOG document, it is emphasized at the outset that many of the measures suggested in this document are based on limited research and evidence. This advice is drawn from various sources available from China [3, 4], Hong Kong [5], Singapore [6], UK [7, 8], Canada [9], continental Europe [10-13] the USA [14, 15] and the WHO [16]. It is a list of recommended practices that are so far believed to be the most effective methods for reducing the transmission of SARS-CoV-2 between patients and healthcare providers.

\section{Important Considerations}

1. Respiratory droplets from coughing, sneezing, loud conversation and direct contact are responsible for the

Ashok Khurana

ashokkhurana@ashokkhurana.com

1 The Ultrasound Lab, New Delhi, India spread of SARS-CoV-2. This happens when body fluids touch another person's eyes, nose or mouth, or an incision, laceration, or abrasion). The disease caused by the virus has been named COVID19.

2. Evidence suggests that healthcare workers must use appropriate PPE, even if they remain further than $1 \mathrm{~m}$ away from a symptomatic patient [17].

3. It is very much possible that carriers may be asymptomatic. It would be prudent, therefore, to presume that every patient and attendant is a potential source of infection.

4. Precautions need to extend way beyond the lockdown period and cannot stop even if the incidence curve of COVID19 flattens or falls.

5. Precautions, tact, knowledge and security measures will be put to test as soon as the lockdown is lifted. There will be a massive patient overload and being prepared is the only answer in this situation.

6. This document is a guidance note and not a compulsory protocol. Every institution/clinic can have a modified protocol to enhance protection.

7. An institution/clinic can opt to remain closed for services as long as the regional law does not enforce the Essential Services Maintenance Act.

\section{Contents of This Statement}

This document includes the following:

1. Peculiarities of an Ultrasound Examination that potentially threaten the Healthcare Professional

2. Indications for performing Ultrasound Scans during the pandemic

3. Patient Scheduling 
4. Patient Evaluation at First Point of Patient Contact, Triaging and appropriate PPE

5. Informed Consent

6. Venue Sanitation and Rearrangement

7. Equipment Sanitation

8. Accelerating Availability of Final Reports

9. Advance Resourcing of Protective Devices and Materials

10. Staff Education

11. Appendix 1: Methods of preparing a $1 \%$ sodium hypochlorite solution

12. Appendix 2: COVID19 Specific Patient Declaration and Informed Consent and Release form.

\section{Threats to Healthcare Professionals During an Ultrasound Examination}

The ultrasound examination has multiple aspects that can increase transmission from the patient to the healthcare worker and vice versa [1, 17] including:

- Small examination rooms

- Absent or restricted natural ventilation

- Closed vent and central (single cooling source, multiple outlet) air conditioning without HEPA filtration

- Insufficient distancing between patient and examiner

- Long examination times

- Transvaginal and invasive procedures

- Coughing, sneezing, loud conversation, anxious deep breathing and sighing by the patient and attendant

- Repeated handling of transducers, machine desktops, keyboards, touch screens, trackballs and recording devices.

\section{Indications for Performing Ultrasound Scans}

Considering the inevitable reduction in resources and capacity, which limits the number of scan appointments available, based on ISUOG guidelines it is recommended that appointments should be triaged to one of the three categories as shown in Fig. 1.

The following indications may be considered:

1. Dating scans between 6 and 10 weeks should be postponed and dating should be done at the Early Morphology 11-13 weeks 6 days scan window.

2. Patients with bleeding per vaginum or pain need appointment prioritization. Bleeding score can be assessed based on pictorial graphs; soakage of 3 pads in an hour would designate as a score of 3 .
3. The Anomalies Scan at 18-20 weeks may be delayed by a few weeks. Even under pandemic circumstances, it is likely that a patient will be able to obtain permission from a District Court along with a Medical Board Opinion for delayed termination in case of a major/lethal anomaly

4. Second trimester scans should be given priority over first trimester scans

5. "Routine" Growth and Doppler scans should be postponed to a 36 weeks assessment. If the pandemic recedes, these can be rescheduled earlier

6. "Decision Making" Growth and Doppler scans between 28 and 41 weeks should be considered on priority. Information from this scan dictates time, place and mode of delivery and this decision may be critical to save lives of mothers and fetuses.

7. The 36 weeks Growth and Doppler scan is a useful triaging tool for early delivery decisions and may need to be carried out although FIGO recommends clinical assessment and delivery during a pandemic.

8. The above-mentioned prioritization will need to be modified depending on extension of lockdown.

\section{Patient Scheduling}

This aspect is critical for the safety of patients, physicians and clinic staff. Adherence to these suggestions will ensure social distancing. Advance Scheduling is necessary and walk in patients are to be discouraged. This should be carried out on the phone by experienced staff. The gap between appointments will vary from institution to institution and should be based on.

1. Staff numbers

2. Availability of waiting spaces

3. Availability of scanning rooms

4. Type of scan

5. Turn around time from arrival of patient to exit.

\section{Patient Evaluation at First Point of Patient Contact, Triaging and appropriate PPE}

This should ideally be carried out on the phone at the time of scheduling an appointment or else when the patient arrives at the clinic. For hospital walk-ins the latter option becomes even more important and must be followed at the time of patient arrival. Recording the temperature is an ideal screen but cumbersome and impractical: handheld non-contact forehead thermometers are in short supply and patients are using paracetamol and not always being 
Fig.1 Basic triage for scan priority

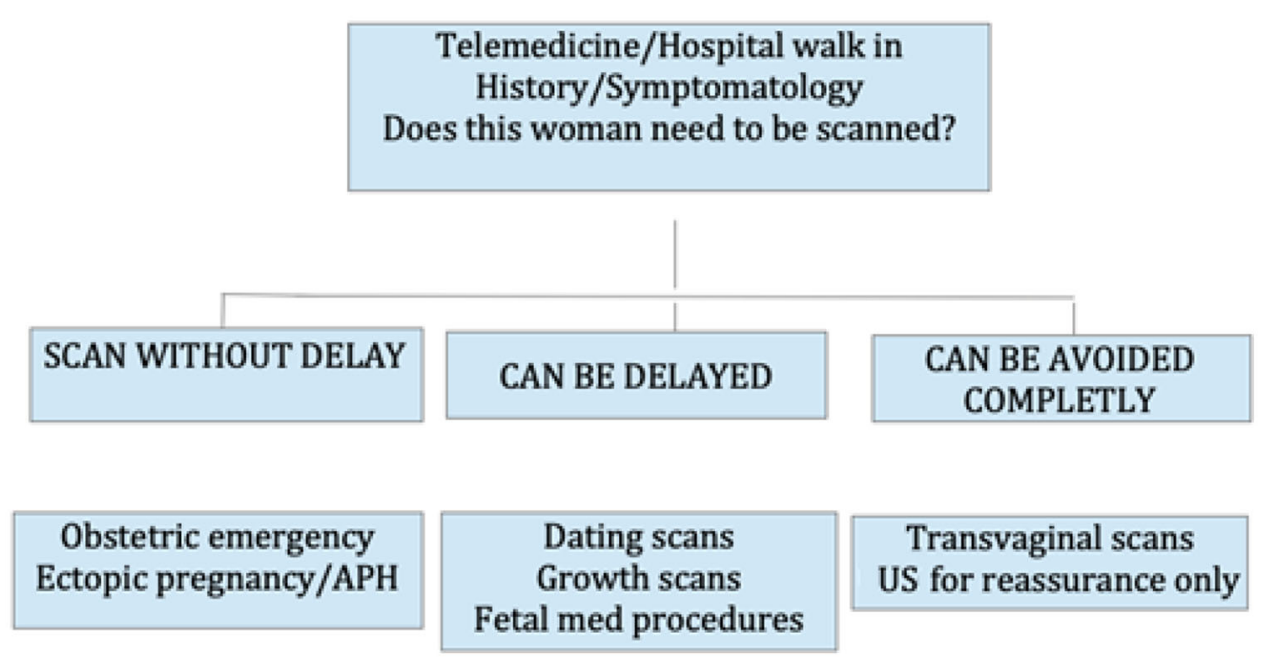

truthful. A history of travel, occupation, contact and cluster (TOCC) is recommended [1]. Experienced staff should be deputed to handle this and a formal form may be used (Appendix 2).

1. Travel should include a detailed itinerary, transit locations and date of return

2. Occupation should be asked as a direct question

3. A history of exposure to a test positive case should be directly asked for

4. A history of living in a known positive cluster or visiting such a cluster should be noted

5. A properly filled declaration and written informed consent document should be obtained from the patient (Appendix 2).

Patients can then be triaged into one of the three categories [1] as shown in Fig. 2.

Based on this categorization, the PPE should be utilized as shown in Table 1.

Patients identified to be at risk for SARS-CoV-2 infection should delay their ultrasound assessment by 14 days. If urgent scan is required, they should be referred to the designated centres for the needy.

\section{Informed Consent}

Informed written consent should be taken from the woman, explicitly stating that she understands that there is a risk of her getting infected by visiting any place during this pandemic and that she also knows that the ultrasound scan needs to be done at this stage (Appendix 2).

\section{Venue Sanitation and Rearrangement}

The following recommendations apply to sanitation [1, 13, 18-20] and logistics. The WHO [16, 21] and Ministry of Health and Family Welfare, Government of India recommendations [18] are particularly useful in this regard.

1. Physical barriers, such as glass or plastic windows panels, should be used to reduce exposure to the COVID19 virus. This approach can be implemented in areas where patients will first present: triage areas, the registration desk at the clinic or the emergency department.

2. Guards at the gate should wear surgical masks and maintain hand hygiene. Conversation should be carried out from a distance of at least $1 \mathrm{~m}$ [21].

3. Alternate seats can be strapped down the middle with string or tape to ensure distance seating.

4. Waiting in a vehicle is safer than waiting in a clinic.

5. Every ultrasound environment is different [1]. It is unlikely that ultrasound clinics have too many choices in ventilation/air conditioning. It is recommended that single unit air conditioning should be run in an "open to outside air" mode (vent open). Clinics will have to decide individually how best to facilitate maximum air change in routine practice. Aerosol generating procedures (AGP) are rare in daily ultrasound practice and should be handled by standard operating procedures by various guidelines [1, 2]. However such AGPs should not be attempted in an ultrasound clinic but in designated centers.

6. All indoor areas such as entrance lobbies, corridors and staircases, escalators, elevators, security guard 
Fig. 2 Triage based on TOCC and symptoms

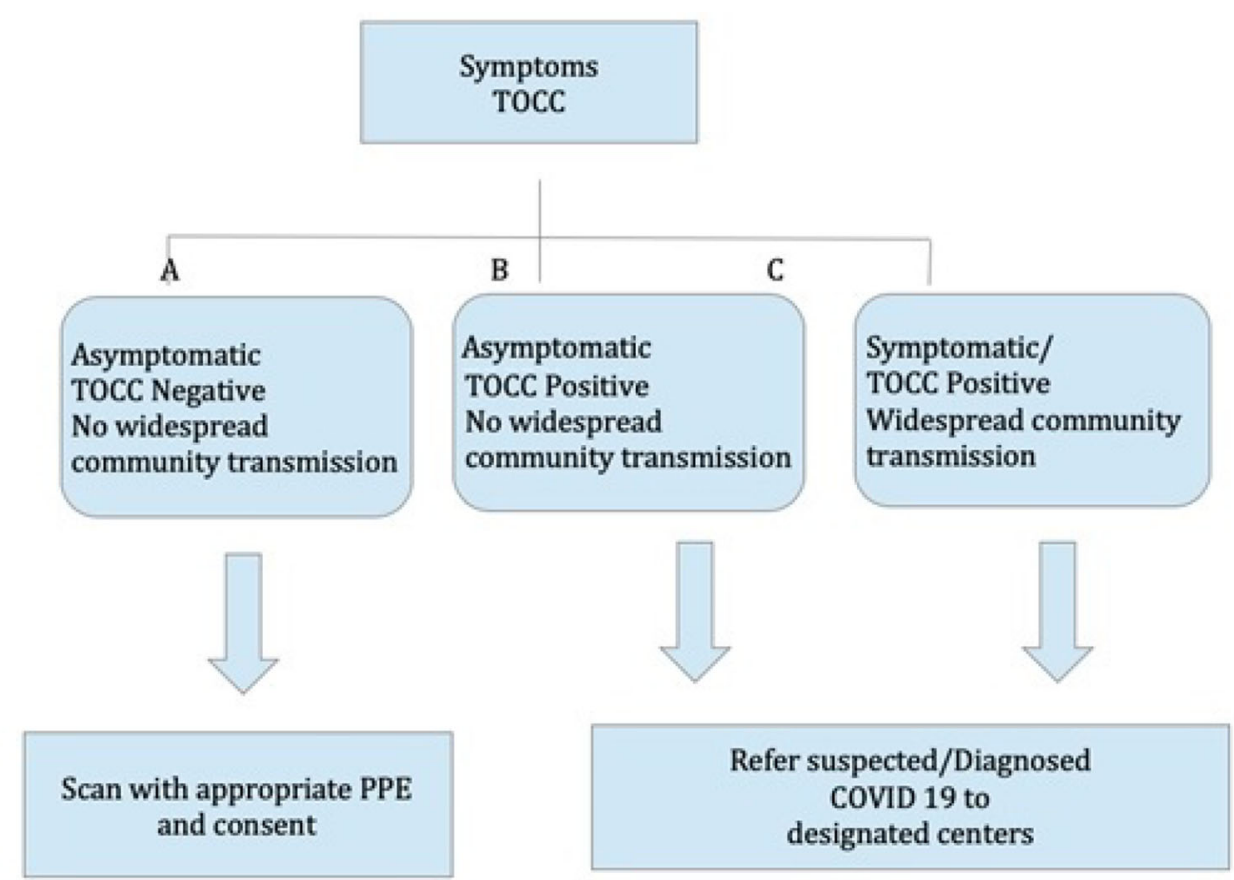

Table 1 PPE requirements based on TOCC and symptoms categorisation

\begin{tabular}{|c|c|c|}
\hline PPE & TOCC A & TOCC B and C (only in COVID designated centres) \\
\hline Clothing & Work clothes & Work clothes \\
\hline Face mask & Surgical/medical mask & N95/FFP2/3 \\
\hline $\begin{array}{l}\text { Hand } \\
\text { hygiene }\end{array}$ & Yes & Yes \\
\hline $\begin{array}{l}\text { Eye } \\
\text { protection }\end{array}$ & No & Yes (goggles) \\
\hline Hair cover & No & Yes \\
\hline $\begin{array}{l}\text { Isolation } \\
\text { gown }\end{array}$ & No & Yes \\
\hline Staffing & - & Bedside scan/minimal staff \\
\hline Disinfection & $\begin{array}{l}\text { Low level disinfection for external/high } \\
\text { level disinfection for internal probes }\end{array}$ & $\begin{array}{l}\text { Low level disinfection for external transducers/high level disinfection for internal } \\
\text { transducers/low level disinfection for ultrasound machines }\end{array}$ \\
\hline
\end{tabular}

booths, office rooms, meeting rooms, pantries and cafeteria should be mopped with a $1 \%$ sodium hypochlorite solution or phenolic disinfectants. Annexure 1 shows details of how to prepare a $1 \%$ sodium hypochlorite solution and has been issued by the Ministry of Health and Family Welfare, Government of India [18]. Phenolic compounds are available as readymade house detergent products in the Indian market. The frequency of mopping will depend on the footfall. At 2-3 patients an hour, $2 \mathrm{~h}$ mopping is recommended. Mopping should also precede the start of work and should also be done after the last patient has departed. Cleaning should be started from cleaner areas and then proceed to dirtier areas. Cleaning staff must wear surgical masks, and heavy-duty gloves. Goggles are required only if there is risk of chemical or organic splash (WHO Rational and Appropriate use of PPE). Appropriate hand hygiene should be practiced.

7. High contact surfaces such elevator buttons, handrails/handles and call buttons, escalator handrails, public counters, intercom systems, telephones, printers/scanners, and other office machines should be cleaned twice daily by mopping with a linen/absorbable cloth soaked in $1 \%$ sodium hypochlorite. 
8. Frequently touched areas like table tops, chairs, chair handles, pens, office files, registers, keyboards, mouse, mouse pad, tea/coffee dispensing machines etc. should specially be cleaned. These can be cleaned with $1 \%$ sodium hypochlorite or a sanitiser that contains at least 60-70\% alcohol.

9. Metallic surfaces like door handles, security locks and keys cannot be adequately cleaned with sodium hypochlorite and a 60-70\% alcohol sanitiser can be used to wipe down these surfaces.

10. Sanitising spray should not be used on potentially highly contaminated areas such as registration counters as it may create splashes that can further spread the virus. A wipe is more effective.

11. Cleaning equipment should be rinsed in running water or hot water after use and left to dry.

12. Hand sanitising stations should be installed near the entry and near high contact surfaces such as clinic registration counters.

13. Toilet floors, toilet pots, toilet seats and lids, toilet sinks and toilet soap dispensers should be cleaned with $1 \%$ sodium hypochlorite or a phenolic detergent three to four times a day. Taps and metallic surfaces should be cleaned with a sanitiser containing 60-70\% alcohol.

14. Outdoor areas have less risk than indoor areas because of air currents and exposure to sunlight. Cleaning and disinfection efforts should be targeted to frequently touched surfaces such as tables and bench handles.

15. Patient examination tables must be covered with sheets (and pillow covers if necessary) that must be changed after each patient. Linen may be disposable as per individual choice. Routine machine-washing with a regular detergent is adequate for non-disposable sheets and pillow covers. Mattresses and table edges must be sanitised using a sanitiser containing 60-70\% alcohol if abundantly available or a $1 \%$ sodium hypochlorite solution.

\section{Equipment Sanitation}

SARS-CoV-2, the causative agent of COVID-19 can be present on surfaces for several days. Surfaces that come into contact with the patient (cable and transducer) as well as surfaces that are touched by the clinician (keyboard, touchscreen, trackball, handlebars, etc.) should be disinfected after each examination. High-level disinfection (HLD) is not required when using ultrasound probes on intact skin. There is no evidence that HLD offers benefit for disinfection from SARS-CoV-2.

The following steps should be followed.
1. Excess ultrasound gel on the transducer should be wiped off with a soft cloth after each examination. Gel can harbor a lot of germs and its presence prevents adequate disinfection.

2. Transducer surfaces and cords should be wiped with an equipment vendor approved low level disinfectant (LLD). Commonly approved agents include $70 \%$ Alcohol, Ammonia, 10\% Bleach, Clorox, standard dilute Cidex, Protex wipes, SaniCloth, PI Spray, Oxivir wipes, Mikrobac, Microzid, Lonza, Klercide 70 and Descocept wipes.

3. Equipment desktop, edges, keyboard, transducer resting stands and especially the side in close proximity to the patient should be wiped with an LLD.

4. Commercial wipes should not be reused. These should be disposed off in appropriate bins. Cloths may be laundered with standard machine-washing.

5. Transducer and cord covers are too overpriced for general use. Makeshift covers like laparoscopy camera covers are difficult to source. These are not encouraged and LLD is adequate.

6. Ultrasound machines in COVID designated centers must be used with machine covers and covers for the transducer and cable. High level disinfectants (HLD) is recommended in areas if ultrasound has been done where AGPs were performed. Details for COVID designated centers are beyond the scope of these guidelines.

\section{Accelerating Availability of Final Reports}

Adequate staff must be available to accelerate preparation of reports. Lockdown conditions do not permit courier services and repeated travel. Reports and Images may be communicated by email/website access.

\section{Advance Resourcing of Protective Devices and Materials}

Pandemic conditions are traditionally accompanied by shortages. All attempts should be made to ensure adequate stock.

\section{Staff Considerations and Education}

Chronologically older (greater than 60 years) staff or those with cardiac disease, pulmonary disorders etc. should be allocated work in areas where they have limited patient contact or may avoid working at all. 
Staff may be rostered to shorter working hours and work in rotation.

Staff must be trained in and given appropriate personal protective equipment and encouraged frequent hand washing. Hands should be washed with regular soap and water for at least $20 \mathrm{~s}$.

The staff must be trained for Phone scheduling, first point of contact interviews, documentation of demographic details and patient history, obtaining informed consent, hand washing, social distancing and donning and doffing PPE.

\section{Concluding Comments}

The basic principles [8] in a situation of pandemic are:

1. Resources should be prioritized and optimised.

2. The emphasis should be on avoiding unnecessary exposure of healthcare personnel to (potentially) infected patients and vice versa.

3. The number of visits should be reduced to the essential minimum.

4. It is wise to consider colleagues, staff and patients as asymptomatic carriers and follow PPE measures

Updates to these guidelines will be notified on the Society of Fetal Medicine website https://www.socie tyoffetalmedicine.org.

\section{Appendix 1}

See Table 2.

\section{Appendix 2}

\section{Patient Demographics, Declaration and Consent Form}

Name \& Address of Medical Organisation

Patient name:

Partner's name:

Attendant's name/s:

Current Address:

Permanent Address:

History of travel

Date of departure from home:

Date of return:

Places/countries visited:

Places of transit

Pilgrimages/Sporting Events/Public Events attended

Occupation:

Partner's Occupation:

History of Contact with a Corona Positive/COVID19 Case: Fever: yes/no Tiredness: yes/no Cough: yes/no Headache: yes/no

Breathing Difficulty: yes/no

Patient Declaration

$\mathrm{I}, \ldots \ldots \ldots \ldots \ldots \ldots \ldots \ldots \ldots \ldots \ldots \ldots \ldots, \quad$ hereby declare that the above information declared by me is correct. I understand that any false declaration can put my health caregivers at serious risk for disease. I agree to follow all precautionary measures advised by the team of Dr........................... and his/her organisation.

I have come for a medically necessary ultrasound scan as evident from my prescription and am aware that there is a COVID19 pandemic. There is a risk of me getting this virus by visiting any place during this pandemic but that

Table 2 Guidelines for the preparation of $1 \%$ sodium hypochlorite solution

\begin{tabular}{|c|c|c|}
\hline Product & Available chlorine (\%) & 1 percent \\
\hline Sodium hypochlorite_liquid bleach & 3.5 & 1 part bleach to 2.5 parts water \\
\hline Sodium hypochlorite-liquid & 5 & 1 part bleach to 4 parts water \\
\hline NaDCC (sodium dichloro-isocyanurate)—powder & 60 & $17 \mathrm{~g}$ to 11 water \\
\hline NaDCC (1.5 g/tablet)_tablets & 60 & 11 tablets to 11 water \\
\hline Chloramine_powder & 25 & $80 \mathrm{~g}$ to 11 water \\
\hline Bleaching powder & 70 & $7 \mathrm{~g}$ to 11 water \\
\hline Any other & \multicolumn{2}{|c|}{ As per manufacturer's instructions } \\
\hline
\end{tabular}


the risk of not doing an ultrasound scan is higher than the risk of contracting the coronavirus and getting COVID19.

I have been explained the content of this declaration in a language that I understand.

I hereby absolve Dr............................ and all members of his/her team/clinic/institution of any punishable or legal liability arising out of my visit and hereby give consent for the same.

Signature of Patient

Signature of Partner/Spouse/Companion

Signature of Attendant

Witness

Date

\section{References}

1. Poon LC, Abramowicz JS, Dall'Asta A, Sande R, ter Haar G, Maršal K, Brezinka C, Miloro P, Basseal J, Westerway SC, AbuRustum RS, Lees C. ISUOG Safety Committee Position Statement: safe performance of obstetric and gynecological scans and equipment cleaning in the context of COVID-19. Ultrasound Obstet Gynecol. 2020. https://doi.org/10.1002/uog.22027.

2. Poon LC, Yang H, Lee JCS, et al. ISUOG Interim Guidance on 2019 novel coronavirus infection during pregnancy and puerperium: information for healthcare professionals [published online ahead of print, 2020 Mar 11]. Ultrasound Obstet Gynecol. 2020. https://doi.org/10.1002/uog.22013.

3. Report of the WHO-China Joint Mission on Coronavirus Disease 2019 (COVID-19). https://www.who.int.

4. Zhang Z, Liu S, Xiang M, Li S, Zhao D, Huang C, Chen S. Protecting healthcare personnel from 2019-nCoV infection risks: lessons and suggestions. Front Med. 2020. https://doi.org/10. 1007/s11684-020-0765-x (Online ahead of print).

5. Yang H, Wang C, Poon LC. Novel coronavirus infection and pregnancy. Ultrasound Obstet Gynecol. 2020;55:435-7.

6. Wong J, Goh QY, Tan Z, Lie SA, Tay YC, Ng SY, Soh CR. Preparing for a COVID-19 pandemic: a review of operating room outbreak response measures in a large tertiary hospital in Singapore. Can J Anaesth. 2020. https://doi.org/10.1007/s12630020-01620-9 (Epub ahead of print).

7. Royal College of Obstetricians and Gynaecologists. Coronavirus (COVID-19) infection and pregnancy. https://www.rcog.org.uk/ globalassets/documents/guidelines/2020-03-26-covid19-preg nancy-guidance.pdf.

8. Abu Rustum RE, Akolekar R, Sotiriadis RA, Salomon LJ, Da Silva Costa F, Wu Q, Frusca T, Bilardo CM, Prefumo F, Poon LC. ISUOG Consensus Statement on organization of routine and specialist obstetric ultrasound services in the context of
COVD19. Ultrasound Obstet Gynecol. 2020. https://doi.org/10. 1002/uog.22029.

9. Revised SOGC COVID-19 Infectious Disease Committee Statement. 2020. https://sogc.org/en/content/featured-news/SOGCInfectious-Disease-Committee-Statement-on-Health-Care-Work ers-during-COVID19Pandemic.aspx.

10. La Marca A. COVID-19: lessons from the Italian reproductive medical experience. https://www.fertstertdialog.com.

11. Istituto Superiore di Sanità. Rapporto ISS COVID-19 n. 4/2020. Indicazioni ad interim per la prevenzione e il controllo dell'infezione da SARS-CoV2 in strutture residenziali sociosanitarie. https://www.epicentro.iss.it/coronavirus/pdf/rapporto-covid-194-2020.pdf.

12. Coronavirus disease 2019 (COVID-19) pandemic: increased transmission in the EU/EEA and the UK-seventh update 25 March 2020. https://www.ecdc.europa.eu.

13. European Centre for Disease Prevention and Control (ECDC), 2020. Infection prevention and control for the care of patients with 2019-nCoV in healthcare settings. 2020. https://www.ecdc. europa.eu/sites/default/files/documents/COVID-19-guidancewearing-and-removing-personal-protective-equipment-health care-settings-updated.pdf.

14. Centres for Disease Control and Prevention. Coronavirus Disease 2019 (COVID-19). Frequently asked questions about personal protective equipment. https://www.cdc.gov/coronavirus/2019ncov/hcp/respirator-use-faq.html.

15. Patel A, Jernigan DB. Initial public health response and interim clinical guidance for the 2019 novel coronavirus outbreakUnited States, December 31, 2019-February 4, 2020 [published correction appears in MMWR Morb Mortal Wkly Rep. 2020 Feb 14;69(6):173]. MMWR Morb Mortal Wkly Rep. 2020;69(5):140-6. https://doi.org/10.15585/mmwr.mm6905e1.

16. World Health Organisation (WHO), 2020. Novel Coronavirus (2019-nCoV). https://www.who.int/westernpacific/emergencies/ novelcoronavirus.

17. Ong SWX, et al. Air, surface environmental, and personal protective equipment contamination by severe acute respiratory syndrome coronavirus 2 (SARS-CoV-2) from a symptomtic patient. JAMA. 2020

18. COVID-19: Guidelines on disinfection of common public places including offices. https://www.mohfw.gov.in.

19. Cleaning and Disinfection for Community Facilities: Interim Recommendations for U.S. Community Facilities with Suspected/Confirmed Coronavirus Disease 2019 (COVID-19). https://www.cdc.gov/coronavirus/2019-ncov.

20. Australian Government Department of Health. Environmental cleaning and disinfection principles for COVID-19. https://www. health.gov.au.

21. Rational use of personal protective equipment for coronavirus disease (COVID-19): interim guidance. https://apps.who.int/iris/ bitstream/handle/10665/331498/WHO-2019-nCoV-IPCPPE_use2020.2-eng.pdf.

Publisher's Note Springer Nature remains neutral with regard to jurisdictional claims in published maps and institutional affiliations. 